\title{
An Outbreak of Hematopoietic and Reproductive Disorders Due to Solvents Containing 2-Bromopropane in an Electronic Factory, South Korea: Epidemiological Survey
}

\author{
Jung-Sun PARK, Yangho KIM, Dong Wook PARk, Kyeong Sook CHOI, \\ Seung-Hyun PARK and Young-Hahn MooN \\ Industrial Health Research Institute, Korea Industrial Safety Corporation (KISCO)
}

\begin{abstract}
An Outbreak of Hematopoietic and Reproductive Disorders Due to Solvents Containing 2-Bromopropane in an Electronic Factory, South Korea: Epidemiological Survey: Jung-Sun PARK, et al. Industrial Health Research Institute, Korea Industrial Safety Corporation (KISCO)_Objectives: This survey was conducted to identify the causative agent in the outbreak in an electronic factory in Korea. Methods: The questionnaire administered to subjects consisted of questions regarding medical and occupational history, including current work practices. Employees were also examined for liver, kidney, brain, reproductive organ and bone marrow function, etc. Detailed investigation of industrial hygiene was conducted to identify the potential source of occupational exposure. Results: Among the three subject groups, all 23 intoxication cases $(6$ males and 17 females) were found in the only section using a new cleaning solution, the Tactile Switch Assembly Operation (total workers: 8 males and 25 females). Abnormal findings in the cases were only hypofunctions of the reproductive organs (ovarian failure, azoospermia or oligospermia) and the bone marrow (pancytopenia). 2-bromopropane is the main component in the cleaning solution (97.4\%). Until late November, 1994, workers were exposed to the cleaning solution directly without using proper protective equipment. The solvent was changed from Freon 113 to the above mixture solution in February, 1994. There has been no case among workers who quit before February, 1994. Freon 113 can therefore be excluded as a possible causative agent in the outbreak. Conclusions: The outbreak in the section of Tactile Switch Assembly Operation was caused by exposure to the new cleaning solution. The causative agent is most likely to be 2-bromopropane.
\end{abstract}

(J Occup Health 1997; 39: 138-143)

Received Nov 25, 1996; Accepted Jan 8, 1997

Correspondence to: $J$.-S. Park, Industrial Health Research Institute, Korea Industrial Safety Corporation (KISCO), 34-6, Kusan-Dong, Bupyeong-Ku, Incheon 403-711, South Korea
Key words: Anemia, Azoospermia, Oligospermia, Amenorrhea

In the summer of 1995 an occupational health manager in an electronic factory of South Korea reported a cluster of cases of secondary amenorrhea among female workers in the section of Tactile Switch Assembly Operation to the Ministry of Labor. We have already reported a case series ${ }^{1)}$ of clinical features about the outbreak. Furthermore, we performed this epidemiological investigation to clarify the association with occupational exposure.

\section{Methods \\ Study subjects}

The observation group totalled 33 workers ( 25 females and 8 males) in the Tactile Switch Assembly Operation Section, and the comparison group totalled 77 workers $(65$ females and 12 males) in the Tactile Switch Processing Operation Section and the General Switch Processing Operation Section. The comparison group was next to the observation group, divided by a wall. In addition, $6 \mathrm{ex}-$ workers ( 3 females and 3 males) who had worked in the Tactile Switch Assembly Operation Section until Feb., 1994, were followed up.

\section{Questionnaire}

All study subjects were interviewed with questionnaires including questions of socio-demographical characteristics, personal life styles, medical and occupational histories, subjective symptoms, and obstetric histories in the case of females.

\section{Clinical examination}

Physical examinations were done together with clinical laboratory tests. The laboratory tests comprised: (1) hematologic investigations such as complete blood count, hemoglobin, and test for bleeding tendency (bleeding time, 
prothrombin time, and activated partial prothrombin time); (2) hormonal studies such as follicle-stimulating hormone (FSH), luteinizing hormone (LH), prolactin, estradiol, and testosterone; (3) kidney and liver function tests; (4) thyroid function test; (5) semen analysis; and (6) others including radiographic studies (chest film), urinalysis, electrocardiogram and electroencephalogram.

The diagnostic criteria for hypofunction of the reproductive system and the bone marrow were as follows:

Hypofunction of ovarian glands: amenorrhea with FSH $\geq 40 \mathrm{mI} . \mathrm{U} . / \mathrm{m} l$,

Hypofunction of sperm germ cells: decreased sperm counts and/or decreased sperm motility (cf. normal value: sperm concentration $\geq 20 \times 10^{6} \mathrm{~m}$, sperm activity progress $>60 \%)^{2 y}$ with FSH $\geq 16 \mathrm{mI} . \mathrm{U} . / \mathrm{ml}$,

Hypofunction of the bone marrow: peripheral platelet count $\leq 100,000$ or $W B C$ count $\leq 3,000$.

\section{Industrial hygiene investigation}

To identify the origin of health hazards in the Tactile Switch Assembly Operation Section where the outbreak occurred, we inspected the work process, materials handled, individual work practice, compliance with personal protective devices and the ventilation system, etc., and collected related documents.

We also analyzed the chemicals handled at present by GC-MSD (Gas Chromatograph Mass Selective Detector, Hewlett Packard 587 I II, USA) according to the NIOSH standard method.

No data were available regarding the air concentrations of the chemicals in the workplace or biological monitoring of solvents. Soon after this report, the operation stopped, and workers have no longer been exposed. To estimate the circumstance of exposure to solvents among the workers during normal work days, we monitored the indoor air concentration of various chemicals used in the sections after setting a simulated condition. A total of 14 area samples were collected to obtain general background information near each cleaning bath and some automatic assembling machines for three hours. Short term exposure level was monitored inside the hood of cleaning baths for $15 \mathrm{~min}$. Indoor air samples were analyzed with a GC (Gas Chromatograph, Hewlett Packard 5890 II, USA).

\section{Statistical analysis}

The differences between subject groups in the general characteristics were identified by Chi-square test. And we compared the incidence rate of disorders in the observation group and comparison group.

\section{Results}

$<$ Health Evaluation $>$

\section{Characteristics of study subjects}

Table 1 shows the characteristics of the study subjects. The drinking habits of the Tactile Switch Assembling workers were not different from those of the comparison group. Most workers in both groups were young females and their smoking rates were low.

\section{Characteristics of disorders}

Bone marrow and testis/ovarian failure were the most common disorders among the 13 female workers reported first. Most of them complained of headache, dizziness and amnesia which were the general signs of toxicity of organic solvents. We could not detect any other abnormalities except

Table 1. Characteristics of the study subjects

( ): \%

\begin{tabular}{clcccc}
\hline Characteristic & Section & $\begin{array}{c}\text { Tactile switch } \\
\text { assembling } \\
(\mathrm{N}=33)\end{array}$ & $\begin{array}{c}\text { Tactile switch } \\
\text { processing } \\
(\mathrm{N}=17)\end{array}$ & $\begin{array}{c}\text { General switch } \\
\text { processing } \\
(\mathrm{N}=57)\end{array}$ & $\begin{array}{c}\chi^{2} \\
\text { (p-value) }\end{array}$ \\
\hline \multirow{2}{*}{ Sex } & male & $8(24.2)$ & $10(58.8)$ & $1(1.8)$ & 30.58 \\
& female & $25(75.8)$ & $7(41.2)$ & $56(98.2)$ & $(0.000)$ \\
Age & -19 & $41(12.1)$ & $0(0.0)$ & $1(1.8)$ & \\
(year) & $20-29$ & $17(51.1)$ & $4(23.5)$ & $48(84.2)$ & 34.84 \\
& $30-39$ & $8(24.2)$ & $5(29.4)$ & $3(5.3)$ & $(0.000)$ \\
& $40-49$ & $4(12.1)$ & $8(47.1)$ & $5(8.8)$ & \\
Marital & unmarried & $19(57.6)$ & $5(29.4)$ & $50(87.7)$ & 29.24 \\
status & married & $11(33.3)$ & $12(70.6)$ & $6(10.5)$ & $(0.000)$ \\
& separated due to death & $3(9.1)$ & $0(0.0)$ & $1(1.8)$ & \\
Smoking & current smoker & $7(21.2)$ & $4(23.5)$ & $1(1.8)$ & 34.34 \\
& ex-smoker & $0(0.0)$ & $4(23.5)$ & $0(0.0)$ & $(0.000)$ \\
& nonsmoker & $26(78.8)$ & $9(52.9)$ & $56(98.2)$ & \\
Alcohol & drinker & $23(69.7)$ & $11(64.7)$ & $33(57.9)$ & 1.28 \\
& nondrinker & $10(30.3)$ & $6(35.3)$ & $24(42.1)$ & $(0.527)$ \\
\hline
\end{tabular}


reproductive and hematopoietic hypofunctions. All subjects were found to have had normal menstruation up to the outbreak, and they had not used any special medications or oral birth control pills during employment. Details of clinical manifestations were included in our case series report ${ }^{1 !}$.

\section{Incidence rates of disorders by subject group}

We confirmed that the outbreak occurred in the only Tactile Switch Assembly Operation Section.

Among 25 female and 8 male workers in the Tactile Switch Assembly Operation Section, 17 females had hypofunction of the ovaries, 6 males had hypofunction in sperm production, and of these, 7 workers ( 1 male and 6 females) had additional hypofunction of the bone marrow. Incidence rates of total disorders by sex were 75 per 100 male workers and 68 per 100 female workers (Table 2).

\section{Incidence rates of disorders by time of employment}

In the Tactile Switch Assembly Operation Section, the cleaning solution was changed in Feb., 1994 from Freon 113, which had been used until then, to a mixture of SPG6AR and Solvent \#5200. We therefore compared the incidence rates among those who quit before Feb., 1994 with those of the workers who have been working in this section since then. Many workers from the latter group had disorders ( 1 of 2 males and 10 of 18 females), whereas nobody from the former group had problems (Table 3 ).
Incidence rates of disorders by time of initial exposure to new cleaning solution

We compared the incidence rates of disorders by time of the initial exposure to the new cleaning solution among workers in the Tactile Switch Assembly Operation Section. There were no problems among those who entered after Aug. 1, 1994. The incidence rates were 100 per 100 male workers and 94.4 per 100 female workers who entered before July 31, 1994 (Table 4).

\section{$<$ Industrial Hygenic Evaluation>}

\section{Process}

The tactile switch assembly operations were done in a room completely separated from other processes. There were seven assembly lines, each with one cleaning bath with a hood attached and three (or four) automatic assembly machines. First, serially connected parts of a tactile switch were delivered to the cleaning bath and dipped in the cleaning solution for several seconds. The solution degreased the parts and also filled the chink between the resin and the terminal of the parts with polytetrafluoroethylene, a solid component in the cleaning solution. This component prevents flux from infiltrating into the chink between the resin and the terminal of the parts when lead soldering is done in a later process, and makes the tactile switch function well. After passing through the cleaning bath, the parts are fed into the automatic assembling machine and assembled into

Table 2. Incidence rates of disorders by work process

( ): incidence rate per 100 workers

\begin{tabular}{|c|c|c|c|c|c|c|c|}
\hline \multirow[b]{2}{*}{ Work process } & \multirow[b]{2}{*}{ Sex } & \multirow[b]{2}{*}{$\begin{array}{c}\text { No. of } \\
\text { workers }\end{array}$} & \multirow[b]{2}{*}{ Normal } & \multirow[b]{2}{*}{$\begin{array}{l}\text { Bone marrow } \\
\text { hypofunction } \\
\text { only }\end{array}$} & \multicolumn{2}{|c|}{ Abnormal } & \multirow[b]{2}{*}{ Total } \\
\hline & & & & & $\begin{array}{l}\text { Reproductive } \\
\text { hypofunction } \\
\text { only }\end{array}$ & $\begin{array}{c}\text { Both } \\
\text { hypofunction }\end{array}$ & \\
\hline Tactile switch & male & 8 & 2 & 0 & 5 & 1 & $6(75.0)$ \\
\hline Assembling & female & 25 & 8 & 0 & 11 & 6 & $17(68.0)$ \\
\hline Tactile switch & male & 10 & 10 & 0 & 0 & 0 & $0(0.0)$ \\
\hline Processing & female & 7 & 7 & 0 & 0 & 0 & $0(0.0)$ \\
\hline General switch & male & 2 & 2 & 0 & 0 & 0 & $0(0.0)$ \\
\hline Processing & female & 58 & 58 & 0 & 0 & 0 & $0(0.0)$ \\
\hline
\end{tabular}

Table 3. Incidence rates of disorders by time of employment in the Tactile Switch Assembly Operation Section

( ): incidence rate per 100 workers

\begin{tabular}{|c|c|c|c|c|c|c|}
\hline \multirow{2}{*}{$\begin{array}{l}\text { Calendar time for } \\
\text { working }\end{array}$} & \multicolumn{3}{|c|}{$\begin{array}{c}\text { Quit } \\
\text { before Feb., } 1994\end{array}$} & \multicolumn{3}{|c|}{$\begin{array}{l}\text { Entered } \\
\text { after Feb., } 1994\end{array}$} \\
\hline & No. workers & normal & abnormal & No. workers & normal & abnormal \\
\hline Male & 3 & 3 & 0 & 2 & 1 & $1(50.0)$ \\
\hline Female & 3 & 3 & 0 & 18 & 8 & $10(55.6)$ \\
\hline Total & 6 & 6 & 0 & 20 & 9 & $11(55.0)$ \\
\hline
\end{tabular}


Table 4. Incidence rates of disorders by time of initial exposure to the new cleaning solution

\begin{tabular}{|c|c|c|c|c|}
\hline \multicolumn{2}{|l|}{ Sex } & $\begin{array}{l}\text { Feb. - July } \\
1994\end{array}$ & $\begin{array}{l}\text { Aug. } 1994- \\
\text { Jan. } 1995\end{array}$ & Feb. $1995-$ \\
\hline \multirow[t]{3}{*}{ Male } & normal & $0(\quad 0.0)$ & $0(\quad 0.0)$ & $0(\quad 0.0)$ \\
\hline & abnormal & $8(100.0)$ & $0(\quad 0.0)$ & $0(0.0)$ \\
\hline & subtotal & $8(100.0)$ & $0(\quad 0.0)$ & $0(\quad 0.0)$ \\
\hline \multirow[t]{3}{*}{ Female } & normal & $1(5.6)$ & $4(100.0)$ & $3(100.0)$ \\
\hline & abnormal & $17(94.4)$ & $0(\quad 0.0)$ & $0(\quad 0.0)$ \\
\hline & subtotal & $18(100.0)$ & $4(100.0)$ & $3(100.0)$ \\
\hline \multirow[t]{3}{*}{ Total } & normal & $1(4.6)$ & $4(100.0)$ & $3(100.0)$ \\
\hline & abnormal & $25(95.4)$ & $0(\quad 0.0)$ & $0(\quad 0.0)$ \\
\hline & subtotal & $26(100.0)$ & $4(100.0)$ & $3(100.0)$ \\
\hline
\end{tabular}

Table 5. Chemical composition of the new cleaning solution

\begin{tabular}{lr}
\hline \multicolumn{1}{c}{ Components } & \multicolumn{1}{c}{$\%$} \\
\hline 2-bromopropane & 97.40 \\
1,1,1-trichloroethane & 0.01 \\
n-heptane & 0.33 \\
1,2-dibromopropane & 0.20 \\
\hline
\end{tabular}

a separate tactile switch. The same cleaning solution was used in all of seven cleaning baths.

Prior to Nov., 1994 there were two uncovered temporary cleaning baths without hoods, and until the outbreak, the automatic infusion system, which supplied cleaning solution to the cleaning baths, was not introduced into the process.

One or two female workers were located on each assembly line. Several times a day they treated disconnected parts inside the hoods of the cleaning baths without using any personal protective devices. Male workers periodically put the cleaning solution into the baths, controlled the concentration of the solution, and checked all of the assembly lines. All the workers did 12-hr shift work.

\section{Materials handled}

In the Tactile Switch Assembly Operation Section no materials were handled except for a cleaning solution. The cleaning solution was introduced as a substitute for Freon which has been known since Feb., 1994 to destroy the stratospheric ozone layer.

The major component of the bulk sample from the present cleaning solution proved to be 2-bromopropane (97.4\%) by GC-MSD analysis. Other components of the solvent were n-heptane $(0.33 \%), 1,2$-dibromopropane $(0.2 \%)$, and $1,1,1$ trichloroethane $(0.01 \%)$ (Table 5$)$.

\section{Evidence of exposure}

The mean \pm standard deviation (range) of the 2 bromopropane concentration from 14 area samples in the tactile switch assembling room was $12.4 \pm 3.13$ ppm (9.2$19.6 \mathrm{ppm}$ ) under a simulated setting (Fig. 1).

Short term exposure level monitored inside the hood of cleaning baths was 4,140.7 ppm in 2-bromopropane, 29.8 ppm in n-heptane and less than 1 ppm in 1,1,1-trichloroethane. Neither benzene nor ethylene glycol ethers were detected in bulk or air samples.

Through the interview with tactile switch assembling workers, we were informed that they had believed the new solvents had little toxicity and had often put their heads inside the hoods of cleaning baths or had dipped their bare hands into the solution without using any personal protective devices.

\section{Discussion}

We confirmed that in the only Tactile Switch Assembly Operation Section a considerable number of the workers had the same disorders, such as hematopoietic/reproductive hypofunction (Table 2). The Tactile Switch Assembly Operation room was separated from other processes by a wall, and its ventilation system was also separate. In the entire factory only this process adopted the 2-crew 2-shift work system (12 hr per shift).

Most workers in the Tactile Switch Assembly Operation Section complained of headache, dizziness and amnesia which are the general symptoms due to organic solvents". We could not find any other abnormalities except reproductive and hematopoietic hypofunctions. Male workers showed signs of germ cell failure, and female workers had ovarian failure with a high FSH blood level and normal prolactin blood level and/or severe ovarian atrophy on the ultrasonogram.

The only material handled in the Tactile Switch Assembly 


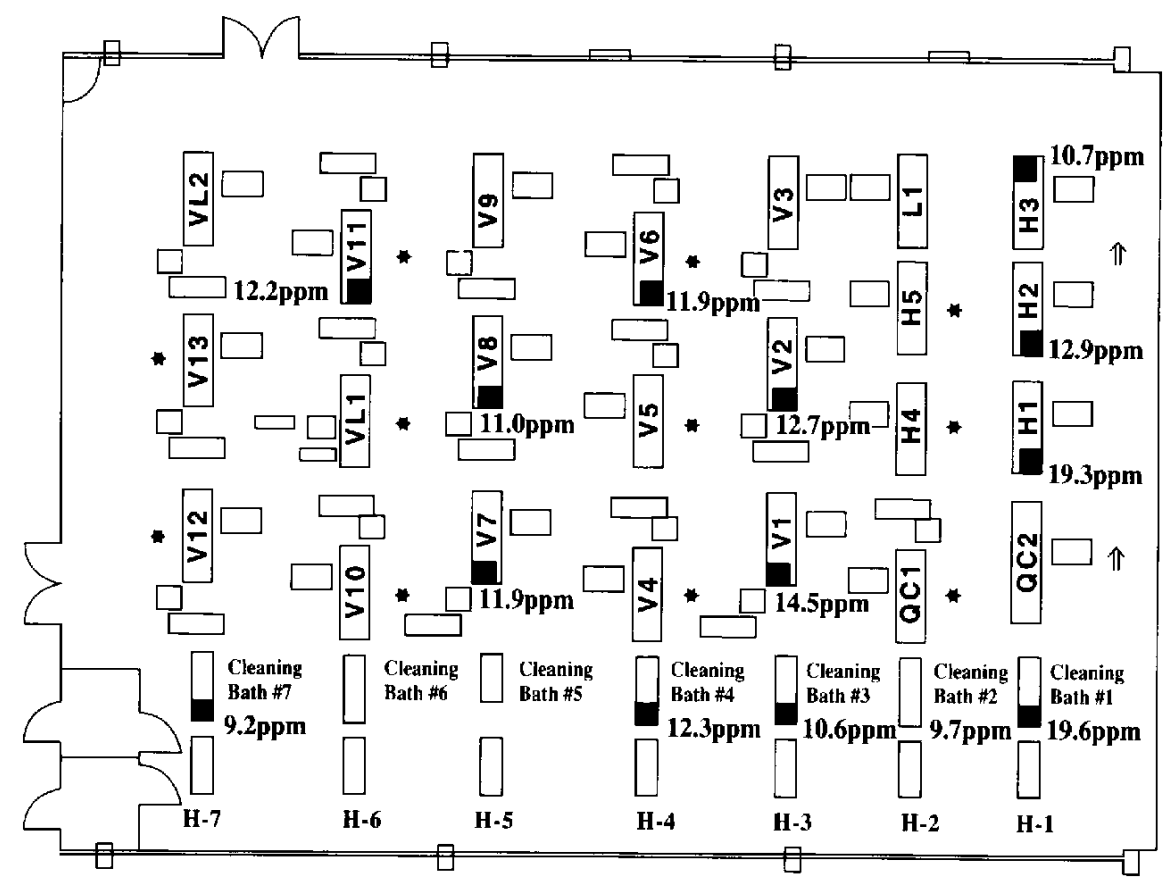

INDEX

$\mathrm{H}-1 \cdot \mathrm{H}-7$ : Assembly lines with Cleaning bath

V1-V10,

VL1-VL2,

H1-H5,

Automatic assembly QC1-QC2, $\}$ machines

L1

- Work positions for

Female workers

Direction of processing

Area sampling spots

Fig. 1. Indoor air concentration distribution for 2-bromopropane under simulated setting in the Tactile Switch Assembly Operation Section.

Operation Section was a cleaning solution. It was a mixture used as a substitute for Freon 113 since Feb., 1994. Freon has lower toxicity in humans and we could not find any abnormalities in those who quit before Feb., 1994 (Table 3). We could therefore exclude Freon as a potential causative agent. As shown in Table 4, the length of exposure to the new cleaning solution was associated with the incidence rates of disorders.

2-Bromopropane, the major component $(97.4 \%)$ in the cleaning solution is very volatile and permeable to the skin. Its vapor pressure is $175 \mathrm{mmHg}$ at $20^{\circ} \mathrm{C}$, and the saturated vapor pressure is $230,263 \mathrm{ppm}^{3}$. Because two uncovered temporary cleaning baths were used $24 \mathrm{hr}$ daily for about 6 months and most of the ventilated air was recirculated in the room, it is assumed that the indoor air concentration of 2 -bromopropane was always very high. And all female workers used to treat unconnected parts inside the hood of the cleaning bath manually by putting their heads into the hood several times a day. All male workers periodically dipped a glass of the cleaning solution from the bath by hand and poured the cleaning solution into the baths to control the concentration of the cleaning solution. In interviews we found that all workers did 12-hr shift work and never used personal protective devices such as gloves and masks. From the above information we infer that both male and female workers in the Tactile Switch Assembly Operation Section had been exposed to the cleaning solution at a considerably high concentration each day. The exposure lasted until August, 1995, when the process was stopped.

We could not identify any known physical or chemical agents responsible for bone marrow and/or germ cell failure, for example ionizing radiation ${ }^{41}$, lead ${ }^{5)}$, formaldehyde ${ }^{6 \text {, }}$, ethylene glycol ethers and their acetates ${ }^{7)}$, benzene ${ }^{8}$, dinitrobenzene ${ }^{9\rangle}$, and dibromochloropropane ${ }^{(0,11)}$, in the workplace. Accordingly, we assumed that the agent responsible for health hazards is likely to be one of the chemicals in the solution, most likely 2-bromopropane. The major component in the cleaning solution is a material whose toxicity is not well known. Therefore its occupational standards have not yet been instituted. Other minor components included in the solution were $n$-heptane and polytetrafluoroethylene. $\mathrm{N}$-heptane, detected in trace amounts in the air, is less likely to be the causative agent of hematopoietic/reproductive disorders, and polytetrafluoroethylene at room temperature, as in this process, is known to be stable. It is notable that 2bromopropane has a chemical structure similar to that of dibromochloropropane which has been reported to cause male infertility and bone marrow depression ${ }^{12,13)}$. We speculate that 2-bromopropane as an alkylating agent might inhibit rapidly proliferating cells such as hematopoietic cells or germ cells of testis/ovary.

By examining medical records, we gained from those who were not included in the study groups other reliable information that further substantiated the causal relationship of the new cleaning solution. Two female ex-workers, who quit their jobs due to pancytopenia in Jan. and Feb., 1995 respectively, recovered their health after cessation of exposure to the new cleaning solution. And the toxicity of 2 -bromopropane was confirmed by animal experiments at 
our institute recently. Twenty-eight days of repeated intraperitoneal dose experiments in male and female Sprague Dawley rats showed similar toxicities to those in humans ${ }^{14)}$.

No previous studies reported human toxicity of 2bromopropane, but our epidemiological investigation led us to the inference that the causative agent for the bone marrow and/or germ cell failure is most likely to be 2-bromopropane.

\section{Conclusion}

We concluded that the outbreak of hematopoietic and reproductive disorders in the electronic factory was caused by the new cleaning solution, and the causative agent is most likely to be 2-bromopropane, the major component of the cleaning solution.

We are also investigating metabolites of 2-bromopropane and the pathogenesis of human reproductive disorders, and observing the progress of all study subjects.

\section{References}

1) Kim $Y$, Jung $K$, Hwang $T$, et al. Hematopoietic and reproductive hazards of Korean electronic workers exposed to solvents containing 2-bromopropane. Scand J Work Environ Health 1996; 22: 387-391.

2) World Health Organization. WHO laboratory manual for the examination of human semen and sperm-cervical mucus interaction. 3rd ed. Cambridge: Cambridge University Press, 1993: 1-107.

3) Lewis R. Sax's dangerous properties of industrial materials. 9th ed. New York: Van Nostrand Reinhold, 1996: 528.

4) Henshaw P. Further problems in X-ray protection II Irradiation injury and the tolerance dose. Radiology 1945;
44: $569-580$.

5) Keogh J. Lead. In: Hazardous materials toxicology, clinical principles of environmental health. Baltimore: William and Wilkins, 1992: 834-844.

6) Barslow S, Sullivan F. Formaldehyde. In: Reproductive hazards of industrial chemicals. London: Academic Press, 1982: 334-345.

7) Kalf G, Post $G$, Snyder R. Solvent toxicology: Recent advances in the toxicology of benzene, the glycol ethers, and carbon tetrachloride. Ann Rev Pharmacol Toxicol 1987: 27: 399-427.

8) Barslow S, Sullivan F. Benzene. In: Reproductive hazards of industrial chemicals. London: Academic Press, 1982: 83-103.

9) Anonymous. Dinitrobenzene. J Appl Toxicol 1989; 9: 199-202.

10) Wills J. Dibromochloropropane. In: Encyclopedia of occupational health and safety 2 nd ed. 1983: 621-623.

11) Gilwerman A, Carlsen N, Keiding N, Skakebaek N. Evidence for increasing incidence of abnormalities of the human testis: A review. Environ Health Perspect 1993; 101, Supplement 2: 65-71.

12) Låg $M$, Soderlund $E$, Omichinski $J$, et al. Effect of bromide and chlorine positioning in the induction of renal and testicular toxicity by halogenated propanes. Chem Res Toxicol 1991; 4: 5287-5534.

13) Lăg M, Omichinski J, Dybing E, Nelson S, Soderlund E. Mutagenic activity of halogenated propanes and propenes: effect of bromine and chlorine positioning. Chem Biol Interact 1994; 93: 73-84.

14) Yu I, Chung Y, Lim C, et al. Reproductive Toxicity of 2bromopropane Scand J Work Environ Health (accepted). 